\title{
Democracia y Liberalismo en Ronald Dworkin ${ }^{*}$
}

\author{
CARLOS RUIZ SCHNEIDER \\ UNIVERSIDAD DE CHILE
}

\begin{abstract}
Resumen: En varias ocasiones Ronald Dworkin, uno de los filósofos del derecho más influyentes hoy, trata en sus trabajos de las relaciones entre constitucionalismo o democracia constitucional, y democracia, o lo que llama democracia mayoritaria. Dentro de estas relaciones, Dworkin aborda lo que entiende por Derechos Individuales, y además establece relaciones entre el Utilitarismo y formas de primacía mayoritaria. En el presente trabajo se analizan dos obras fundamentales de Dworkin, Los Derechos en Serio y un ensayo sobre el Liberalismo; y en ellas se verán los conceptos de Democracia y Liberalismo.
\end{abstract}

Palabras Clave: Ronald Dworkin, Democracia, Liberalismo, Derechos Individuales.

Abtract: In several occasions in Ronald Dworkin`s works, one of the most influential legal philosopher today, he deal with the relations between constitutionalism or constitutional democracy, and democracy, o what he called majoritarian democracy. Inside this relations, Dworkin discuss about what he understands of the concept of Individual Right, and also he establish relations between Utilitarianism and types of majoritarian primacy. In the present paper it is going to be analyze two fundamental works of Dworkin, Taking Right Seriously and an essay of Liberalism; and in these we will see the concepts of Democracy and Liberalism.

Keywords: Ronald Dworkin, Democracy, Liberalism, Individual Rights.

En varias ocasiones en sus trabajos trata Ronald Dworkin, uno de los filósofos del derecho más influyentes hoy, de las relaciones entre constitucionalismo o democracia constitucional (términos con los que identifica sobre todo a la democracia de los Estados Unidos), y democracia, o lo que llama democracia mayoritaria (con la que identifica a casi todos los otros regímenes democráticos existentes). Al examinar estas relaciones, Dworkin defiende el modelo de democracia constitucional en base a la idea de que él permitiría limitar el poder de la mayoría a partir de una especie de dique constituido por los derechos individuales, concebidos como "cartas de triunfo políticas en manos de los individuos." Los individuos, sostiene Dworkin, "tienen derechos cuando por alguna razón, una meta colectiva no es justificación suficiente para negarles lo que, en cuanto individuos, desean tener o hacer, o cuando no justifica suficientemente que se les imponga alguna pérdida o perjuicio" (Dworkin, 1977 (1984) p. 37). Al elaborar estas ideas posteriormente, Dworkin identifica a estas metas colectivas con, por ejemplo, decisiones democrático-mayoritarias, sosteniendo que la teoría democrática implícita en el régimen político estadounidense no es una democracia mayoritaria, sino una democracia constitu-

* Versión escrita de la ponencia presentada por el profesor Ruiz en el II Congreso Estudiantil de Derecho y Teoría Constitucional. 
cional que deja un lugar para que los derechos de los individuos no sean simplemente invalidados por la mayoría, lo que le parecería contrario a la equidad.

$\mathrm{Al}$ intentar justificar esta posición, Dworkin establece una relación entre los defensores de las decisiones mayoritarias y el utilitarismo, y entre su propia postura a favor de la primacía de los derechos, y una posición rawlsiana o kantiana

Voy a examinar fundamentalmente dos trabajos clásicos de Dworkin sobre el tema, Los derechos en serio de 1977, y su ensayo sobre el Liberalismo publicado en el libro colectivo Public and private morality de 1978. Aunque Dworkin ha escrito varios otros ensayos sobre temas relacionados con el que voy a tratar en esta ponencia, me parece que una parte importante de su visión está contenida en estos primeros textos. En todo caso, para completar la interpretación que propongo, habría que incluir estos trabajos posteriores, por lo que lo que presento ahora hay que considerarlo sobre todo como una hipótesis de un trabajo en curso.

Estas ideas de Dworkin sobre democracia y liberalismo han sido objeto de numerosas críticas. Para ejemplificar sobre estas críticas, voy a referirme brevemente al ensayo sobre Política constitucional y derecho constitucional de Bruce Ackerman; a un trabajo de Jeremy Waldron, Derechos y mayorias: Rousseau revitalizado, y a un ensayo más reciente de un filósofo político francés, Jean-Fabien Spitz, sobre La concepción dworkiniana de la democracia y sus críticos, que incorpora también a estos autores, para finalizar con algunas observaciones de Hannah Arendt sobre el constitucionalismo y las libertades liberales.

En los derechos en serio de 1977, Dworkin desarrolla la temática que he esbozado en el contexto de una visión de gran alcance, en la que se trata de justificar una teoría liberal del derecho frente al positivismo y al utilitarismo. Como se sabe, y específicamente contra la concepción de Herbert Hart, Dworkin sostiene que el derecho no puede ser concebido integralmente como una combinación de distintos tipos de reglas sociales, sino que debe incluir también lo que denomina principios, los que en definitiva remiten a derechos individuales. Hay que diferenciar, nos dice Dworkin, rigurosamente a estos argumentos basados en principios, de las reglas sociales, pero también de los "argumentos políticos, que justifican una decisión política demostrando que favorece o protege alguna meta colectiva de la comunidad en cuanto todo" (Dworkin, 1977, p. 148).

Según Dworkin, es una concepción como ésta la que es coherente con la doctrina constitucional de los Estados Unidos que no es una simple teoría mayoritaria. "La Constitución - sostiene - y particularmente el Bill of Rights, está destinada a proteger a los ciudadanos, individualmente y en grupo, contra ciertas decisiones que podría querer tomar una mayoría de ciudadanos, aún cuando esta mayoría actúe siguiendo lo que para ella es el interés general o común" (Dworkin, 1977, p. 211). La expresión que la Constitución estadounidense da al principio de la división de los poderes y algunas sentencias judiciales fundamentales, le otorgan a la Corte Suprema de ese país el poder de revisar las decisiones legislativas en función de estándares constitucionales, y con ello, la posibilidad de defender estos derechos frente a las decisiones mayoritarias. Muchos jueces y teóricos constitucionales estadounidenses han criticado este poder, basándose en el carácter no democrático de la Corte. Si se mira más de cerca a la génesis de éstas y otras disposiciones constitucionales, por ejemplo a través de la justificación que propone Madison en El Federalista, parece claro, como lo muestra por ejemplo Isaac Kramnick en el prólogo a su edición de El Federalista, que ellas apuntan a limitar la democracia y los niveles de participación política en los estados, la que amenazaba seriamente al orden social y económico de las antiguas colonias.

Dworkin rechaza la idea de que los parlamentos y otras instituciones democráticas tengan títulos especiales para tomar decisiones constitucionales. Sostiene que "esta es una posición que, como con frecuencia se ha señalado, pasa por alto el hecho de que las decisiones referentes a derechos en contra de la mayoría no son problemas que equitativamente deban quedar librados a la mayoría. El 
constitucionalismo - la teoría de que a la mayoría hay que restringirla para proteger los derechos individuales - puede ser una teoría buena o mala pero es la que han adoptado los Estados Unidos (cuestión que para nosotros no es muy relevante), y hacer que la mayoría sea juez en su propia causa parece incongruente e injusto. Es decir que los principios de equidad no hablan en favor del argumento de la democracia sino en su contra (esta consideración sí que es pertinente).” (Dworkin, 1977, p.223, paréntesis de C.R.). Lo esencial de una afirmación de derecho, subraya Dworkin, "incluso en un análisis de los derechos tan desmitologizado como el que estoy haciendo, consiste en que un individuo tenga derecho a ser protegido contra la mayoría, incluso al precio del interés general" (Dworkin, 1977, p. 229).

En su ensayo sobre Liberalismo, publicado poco después de Los derechos en serio, Dworkin insiste en esta tensión entre liberalismo y democracia. Sostiene en el ensayo que lo que llama "moralidad derivada" del liberalismo lo llevará a comprometerse con el desarrollo de dos instituciones, la economía de mercado y la democracia. "La democracia - señala Dworkin - está justificada porque protege el derecho de cada persona al respeto y la consideración como un individuo; pero en la práctica la decisión de una mayoría democrática puede violar a menudo ese derecho, de acuerdo a la teoría liberal de lo que ese derecho requiere" (Dworkin, 1979, 134). Así, nos dice nuestro autor, el liberal, conducido hacia el mercado económico y la democracia política por distintas razones igualitarias (y Dworkin ha definido el tema de la igualdad como central en la postura del liberalismo), se encuentra con que estas instituciones van a producir resultados desigualitarios, a menos que agregue a este esquema diferentes tipos de derechos individuales. Estos derechos funcionarán como cartas de triunfo en manos de los individuos; les permitirán resistir decisiones particulares a pesar del hecho que esas decisiones pudieran derivarse del funcionamiento normal de instituciones que no serían cuestionadas" (Dworkin, 1979, p. 136).

\section{II}

Como lo sugerí al comenzar, se han desarrollado muchas críticas a estas posiciones de Ronald Dworkin. Una de las más importantes es, probablemente, la de otro filósofo del derecho y partícipe en los debates de los ' 80 sobre la teoría de la justicia, Bruce Ackerman, especialmente en el ensayo que mencioné antes y que está recogido en su libro Nosotros el pueblo.

Ackerman incluye la concepción de Dworkin sobre la democracia en la escuela que denomina "fundacionalismo de los derechos", en la que autores como Epstein, Owen Fiss y el propio Dworkin convergirían en que "la Constitución Americana -dice Ackerman- está comprometida en primer lugar y fundamentalmente con (la) protección (de los derechos). Ciertamente -señala Ackerman todo el punto de tener derechos es que ellos triunfen sobre decisiones de instituciones democráticas que por otra parte tienen la autoridad legítima para definir el bienestar colectivo". (Ackerman, Yale Law Journal Vol 99, № 3, 1989, p. 466). Las objeciones que insisten en el carácter problemático que tiene la justificación de estos derechos contra las decisiones democráticas, no impresionan a estos autores según Ackerman, mucho más preocupados "por el hecho que incluso un parlamento democrático podría apoyar cualquier número de acciones opresivas - establecer una religión, autorizar la tortura...; y cuando esos ultrajes ocurran, el fundacionalista insiste en que las cortes intervienen a pesar del quiebre del principio mayoritario. Los derechos triunfan a la democracia. Siempre que sean dice Ackerman - los derechos correctos." (Ackerman, 1989, p.467). Porque aquí está la dificultad, nos dice el autor. La dificultad es la arbitrariedad a la que abrimos paso cuando nos internamos por los senderos de este discurso fundacionalista, que recurrirá frecuentemente a la autoridad de filósofos como Kant, por ejemplo Rawls o Dworkin, o Locke como el caso de Nozick para fundar en verdad la primacía de los derechos. 
La respuesta de Ackerman, a la teoría tradicional llamada por él monista, es una teoría o concepción dualista de la democracia, para la cual la fijación de derechos fundamentales es también una decisión democrática, sólo que se trata de una decisión con requisitos más exigentes que los de una mayoría ocasional en un parlamento. A estas decisiones, democráticas también, pero de nivel más alto, por así decirlo, Ackerman las denomina decisiones "del pueblo" o de "nosotros el pueblo". Ackerman describe a estas decisiones "del pueblo", de la manera siguiente: "Las decisiones del Pueblo ocurren raras veces y bajo condiciones constitucionales especiales. Antes de ganar la autoridad de incluir sus propuestas en el derecho más elevado de la nación, un movimiento político debe, primero, convencer a un número extraordinario de sus conciudadanos de tomar la iniciativa propuesta con una seriedad que ellos no dan normalmente a sus opciones políticas; en segundo lugar se debe permitir a los opositores oportunidades justas de organizar sus propias fuerzas; en tercer lugar se debe convencer a una mayoría de ciudadanos para que apoyen estas iniciativas de transformación en la medida en que sus méritos se discutan una y otra vez en los diferentes foros deliberativos provistos por el orden constitucional dualista para estos propósitos.” (Ackerman, 1989, p. 461). Estas son, por otra parte, piensa Ackerman, las maneras como se ha llegado a los grandes principios, en materia de derecho, propios del sistema estadounidense, como por ejemplo, la abolición de la esclavitud o el New Deal, y no necesariamente a través de decisiones de la Corte Suprema.

Así concebido el dualismo, sostiene Ackerman, a través de este sistema de dos vías para la legislación democrática, "permite un lugar importante para la visión de los "derechos como cartas de triunfo", sin violar el compromiso profundo del monista (o sea el demócrata más tradicional) con la primacía de la democracia." (Ackerman, 1989, p. 467).

En el artículo de Spitz, que también mencioné al comienzo, editor francés de Locke y del libro de John Pocock sobre el Momento Maquiaveliano, se parte por el análisis de algunos de los nuevos textos de Dworkin en que se trata del tema de la democracia.

Como en los ensayos que comentamos más arriba Dworkin desarrolla aquí la tesis de una fundamentación moral independiente de los derechos en la idea de origen kantiano de la dignidad humana y la igualdad de consideración y respeto. Lo nuevo de estos ensayos radicaría más bien en sus nuevas críticas a la democracia mayoritaria y a la idea de autogobierno y en la incorporación del tema del constitucionalismo al significado mismo de la democracia. En ésta encontraríamos así dos formas de igualdad según Dworkin, de las que la más profunda corresponde a lo que en los trabajos que hemos analizado identificaba con los derechos. Lo que me parece interesante del texto de Spitz, sin embargo, son las críticas que recoge a las teorías dworkinianas sobre la democracia.

Para la primera de estas críticas el problema consiste en saber si la interpretación de los principios abstractos que propone Dworkin es una cuestión de verdad y de racionalidad. "Cuando nos preguntamos si tal o tal decisión colectiva respeta de manera igual a todos los ciudadanos, no se trata dice Spitz - de encontrar la verdad, porque no es plausible que entre los partidos en liza uno esté en lo verdadero y el otro en lo falso, sino que se trata de inventar una solución capaz de atraer al conjunto de los partidos en presencia. Esta solución no es una respuesta a una cuestión filosófica intemporal que se refiere a la mejor interpretación posible del principio igualitarista abstracto, sino una solución politica dada en una coyuntura particular y susceptible de encontrar apoyo en el conjunto de quienes participan en el debate..." (Spitz, 2001, p. 293). A los ojos de los críticos de Dworkin, según Spitz, "el desacuerdo es entonces inevitable en toda situación política que se pueda considerar como tal. En este sentido, forma parte de lo que podría llamarse las "circunstancias de la política" y es vano buscar una situación de racionalidad perfecta en la cual los individuos podrían tomar decisiones sin ser afectados por la parcialidad que los anima de ordinario." (Spitz, 2001, p. 293-294). Esta primera crítica insiste entonces sobre la idea de "que las instituciones democráticas poseen una ventaja mayor desde el punto de vista de la legitimidad. En política, frente a los hechos del pluralismo razonable -nos dice Spitz- la 
cuestión no es saber quien tiene razón, sino a quien se reconoce la autoridad, es decir, el rol de decidir en un conflicto o de elegir entre posiciones que están en una situación de desacuerdo razonable" (Spitz, 2001, p. 294).

Algunas de las ideas que analiza Spitz, provienen en verdad de los trabajos del filósofo neozelandés Jeremy Waldron. Para Waldron lo esencial es volver a analizar la visión que tiene Dworkin de la voluntad mayoritaria. Waldron piensa que "sería imposible que hubiera regímenes libres y respetuosos de los derechos, si los ciudadanos fueran necesariamente incapaces de plantear y resolver en el proceso político, cuestiones de principio. Si fuera cierto que todas las decisiones colectivas no son sino la expresión de la voluntad de los intereses individuales acumulados del conjunto de los participantes - y si fuera cierto que algo como la voluntad general rousseauista es un mito pura y simplemente, es decir, que no es nunca posible que los ciudadanos se planteen la cuestión de lo que es bueno para el conjunto de la comunidad - no podría haber ningún régimen político libre porque sería imposible que hubiera actos políticos que plantearan principios, como por ejemplo, declaraciones de derechos." (Waldron, citado en Spitz, 2001, p. 295).

De acuerdo a Jeremy Waldron, entonces, "la voluntad mayoritaria no es...siempre de mala calidad." (Waldron, citado en Spitz, 2001, p.295). Una teoría de este estilo sería demasiado pesimista, dice Waldron, "porque negaría la posibilidad de que una mayoría esté nunca en el origen de restricciones constitucionales a su propio poder, salvo por accidente. Si se quiere pensar en proteger los derechos en un sistema democrático, hay que pensar que es posible convencer a una mayoría de ciudadanos,... de que esos derechos son necesarios y que conviene respetarlos". La idea, dice Waldron, de que pudiera haber derechos "contra la voluntad permanente y deliberada de la mayoría carece de sentido y de alcance práctico" (Waldron, citado en Spitz, 2001, p.295).

Waldron propone entonces que se considere la posibilidad de una concepción rousseauniana de la democracia y no solamente la posibilidad de una concepción utilitaria, que ve como supuesto en las críticas a la concepción mayoritaria por Dworkin, por ejemplo. "En la democracia benthamiana -dice Waldron- los votos individuales sólo representan satisfacciones individuales, no expresan nada sobre el equilibrio adecuado entre el individuo y la sociedad. Toda preocupación sobre esta relación tiene que ser externa al proceso de votación. Pero en el modelo de Rousseau, los votos ya expresan una opinión sobre el equilibrio adecuado entre ambos. Sopesar esta relación es algo intrínseco a lo que ocurre con la decisión del votante individual. Puede, por lo tanto, que haya mayores dificultades en justificar naturalmente constricciones institucionales externas en una democracia rousseauniana, porque los derechos debieran ya haber sido tomados en cuenta por los ciudadanos en su voto y deliberación” (Spiz, p. 296).

Como se ve aquí está uno sobre todo ante concepciones opuestas y diferentes de la democracia y no solamente ante la posibilidad de una visión utilitaria, está aquí también en juego concepciones diferentes del significado de lo público y de la opinión pública.

El liberalismo en el estilo del de Dworkin no deja de recordarnos una visión de la voluntad mayoritaria y la opinión pública similar a la de los liberales del siglo XIX.

John Stuart Mill, deplora, por ejemplo, así el "yugo de la opinión pública” y el "medio de coacción moral que es la opinión pública". "En la vida del Estado, decir que la opinión pública gobierna al mundo suena a tópico. El único poder que conserva aquí todavía su buen nombre es el de las masas y el de aquellos gobiernos que se convierten en instrumentos de las exigencias y las inclinaciones de las masas. Y lo que constituye una novedad aún más significativa, las masas crean actualmente sus propias opiniones -se sorprende Mill-... De la elaboración intelectual de esas opiniones cuidan hombres de poco más o menos la misma catadura, los cuales bajo el impulso del momento se dirigen a ellas a través de los periódicos." (John Stuart Mill, citado en Habermas, p. 164). 
Frente a esta desconfianza elitista liberal frente a la democracia, y en general frente a la política, una concepción como la que se puede entrever en Waldron y también en Ackerman resulta relativamente próxima de una concepción de la política que puede encontrarse, por ejemplo, en Hannah Arendt, y que me parece también muy sugerente.

Aunque el objetivo de Arendt no es en realidad una defensa de la democracia, sino más bien de la esfera pública y política, junto a un intento de rescatar el sentido del poder político de la impronta de la violencia y la dominación, comparte con los autores que acabo de mencionar sus reservas frente al "constitucionalismo", y una defensa del significado y las proyecciones políticas de la opinión pública y de lo que podría llamarse la participación democrática.

Señala Arendt en su libro Sobre la Revolución que si los hombres que, a ambos lados del Atlántico “estaban preparados para la revolución, tenían algo en común... era una apasionada preocupación por la libertad pública, en el modo en que Montesquieu y Burke hablaban de ella". De acuerdo al testimonio de John Adams la revolución comenzó antes que la guerra, porque los habitantes de las colonias fueron "formados por la ley en torno a corporaciones y cuerpos políticos" y poseían "el derecho de reunirse en sus municipios, para deliberar allí sobre los negocios públicos" (John Adams, citado por Arendt, 1963 p. 118). En palabras de Tocqueville, "tenían el gusto y la pasión de la libertad pública".

Según Arendt, el uso americano habla de la felicidad pública donde los franceses hablan de libertad pública. "El punto es - señala - que los americanos sabían que la felicidad pública consiste en participar en los asuntos públicos y que las actividades dedicadas a ellos no constituyen una carga sino que otorgan a los que las realizan en público, un sentimiento de felicidad que no pueden adquirir en ningún otro lugar" (Arendt, 1963, p. 119). Y agrega que con ocasión de los grandes mítines que se desarrollaban en paralelo a la lucha revolucionaria del pueblo norteamericano “...el pueblo asistía a las asambleas...no a causa de alguna obligación y menos para servir sus propios intereses, sino sobre todo porque disfrutaba de las discusiones, las deliberaciones y la formación de decisiones...Lo que los movía era una pasión por la distinción...Cada individuo se ve fuertemente influido por un deseo de ser visto, escuchado e interpelado o aprobado y respetado por la gente cercana...estas son de hecho, psicológicamente, -dice Arendt- las principales virtudes y vicios del hombre político, porque la sed y la voluntad de poder como tal, sin considerar alguna pasión por la distinción...es la cualidad que tiende a destruir toda la vida política...(Arendt, 1963, p.119).

En este sentido, nos dice la autora, conviene recordar que la ausencia de libertad política bajo el régimen del absolutismo ilustrado "no consistió tanto en la denegación de algunas libertades personales -que existían- como en el hecho de que el mundo de los asuntos públicos...era invisible..." (Arendt, 1963, p. 124).

La idea central de la revolución es la fundación de la libertad, según Arendt esto significa la fundación de un cuerpo político que garantice el espacio donde la libertad puede aparecer. Para los modernos, este acto de fundación es idéntico a dar forma a una constitución.

Para los hombres del siglo XVIII, sin embargo, era claro todavía que si necesitaban una constitución era para establecer los límites del nuevo dominio político y para definir sus reglas internas, que tenían que fundar y construir un nuevo espacio público dentro del cual la "pasión por la libertad pública" o la "búsqueda de la felicidad pública" iban a poder ejercitarse por las generaciones por venir, de modo que su propio "espíritu revolucionario" pudiera sobrevivir al fin de la revolución. Es a esta libertad a la que llamaron "felicidad pública" y consistió en el derecho del acceso del individuo al dominio público, en su participación en el poder público, en ser "un partícipe en el gobierno de los asuntos", en la expresiva frase de Jefferson.

Pero el énfasis cambió casi de inmediato, según Arendt, desde los contenidos de la Constitución, esto es la creación y el compartir el poder y el ascenso de un nuevo dominio, donde -en palabras de Madison - "la ambición sería controlada por la ambición (pero - dice Arendt- por supuesto la ambi- 
ción de destacar...no la ambición de hacer carrera), a la Declaración de los Derechos, que contenía los frenos constitucionales necesarios al gobierno; se desplazó, en otras palabras, desde la libertad pública, a las libertades civiles, o desde el compartir en los asuntos públicos por mor de la felicidad pública, a una garantía de que la persecución de la felicidad privada iba a ser protegida y promovida por el poder público". (Arendt, 1963, p. 135).

En este sentido, nos dice Arendt, la "conversión del ciudadano de la revolución en el individuo privado de la sociedad del siglo XIX, ha sido descrita a menudo en términos de la Revolución Francesa, que hablaba de ciudadanos y burgueses. En un nivel más sofisticado podemos considerar esta desaparición del 'gusto por la libertad pública' como el retiro del individuo a un 'dominio interno de la conciencia' donde encuentra la única 'región apropiada de libertad humana'; desde esta región, el individuo que ha ganado para sí a lo mejor del ciudadano, se defenderá entonces, como desde una fortaleza, contra una sociedad que, a su vez, extrae lo mejor de la individualidad" (Arendt, 1963, p. 140).

Por el contrario, como lo hemos visto, el propósito de los revolucionarios, tanto franceses como americanos era, no era "cómo limitar el poder, sino cómo establecerlo; no cómo limitar el gobierno, sino cómo fundar un nuevo gobierno...y el establecimiento de un nuevo poder no podría estar basado en lo que siempre había sido una negativa del poder, esto es, en una declaración de derechos". (Arendt, 1963, p. 148).

En realidad estas ideas de Arendt sobre el poder deben complementarse con la distinción, que ella ha fundamentado en su artículo sobre la violencia, entre poder y violencia, es decir, entre una acción en común, sustentada en la opinión, y la mera fuerza. Es en este sentido que Arendt interpreta la afirmación de Montesquieu según la cual sólo el poder detiene al poder, a lo que habría que agregar, dice Arendt, que lo detiene "sin destruirlo, sin introducir impotencia en el lugar del poder" (Arendt, 1963 , p. 151). Esto porque, agrega nuestra autora, es evidente que "el poder puede ser destruido por la violencia; esto es lo que sucede en las tiranías, donde la violencia de uno destruye el poder de los muchos, tiranías que, al decir de Montesquieu, sin embargo, se destruyen a su vez internamente porque engendran impotencia en lugar de poder. Pero el poder, contrariamente a lo que tendemos a pensar, no puede ser controlado, por lo menos no de manera confiable, por las leyes, porque el así llamado poder del gobernante que es controlado en el gobierno constitucional, limitado y legal, no es de hecho poder sino violencia, es la fuerza multiplicada del uno que ha monopolizado el poder de los muchos". (Arendt, 1963, p. 151).

Como puede verse entonces, después de este rápido desarrollo, la idea de Arendt es que el constitucionalismo y la idea de los límites al poder, y esta idea de los derechos, se fundan en una confusión entre la libertad pública y las libertades civiles, entre el poder y la violencia. Y esto, en definitiva, porque en el constitucionalismo falta un concepto adecuado de la política y de los conceptos vecinos de poder, acción y participación activa en los asuntos públicos.

Creo, para terminar, que una concepción como la de Arendt, contribuye a hacer visibles los límites de la idea dworkiniana de la democracia, mostrando que esta concepción es una concepción muy estrecha de lo que está en juego en la acción política y que promueve, además, una concepción de la democracia que la expurga de todo contenido de participación y de "libertad" o de "felicidad pública", en términos de Arendt, para reducirla a una búsqueda de una suma de felicidades privadas.

\section{Referencias bibliográficas}

Arendt, Hannah, On Revoloution, Penguin, 1963.

Ackerman, Bruce, “Constitutional Law/ Constitutional Politics", Yale Law Journal, Vol. $99 \mathrm{~N}^{\circ}$ 3, 1989 . 
Dworkin, Ronald, Los Derechos en Serio, Ariel, 1984.

- "Liberalism" en S. Hampshire (Ed.) Public and Privatemorality, 1978.

Habermas, Jürgen, Historia y Crítica de la opinión pública, Barcelona, 1981.

Spitz, Jean-Fabrien, "La conception Dworkinienne de la démocratie et ses critiques" en $\underline{\text { Archives }}$ de la Philosophie du Droit, 45 (2001).

Waldron, Jeremy, The dignity of Legislation, Oxford, 1999.

"Rights and majorities. Rousseau revisited" en Liberal Rights, Collected Papers 1981-1991, Cambridge, 1991. 